\title{
El arte de describir el territorio: mapas y planos históricos en torno al puente de Alcántara (Cáceres, España) ${ }^{1}$
}

\author{
The art of describing the territory: historic maps and \\ plans of the bridge of Alcántara (Cáceres, España)
}

P. Chias $^{(*)}$, T. Abad $\left.{ }^{*}\right)$

\section{RESUMEN}

El estudio de la construcción del territorio y del paisaje a diferentes escalas se ha basado tradicionalmente en fuentes documentales escritas, y en menor medida en las gráficas. Las fuentes cartográficas, junto a los cuadros, los dibujos, las fotografías y otras fuentes no verbales han sido frecuentemente relegadas o consideradas de una categoría inferior, muchas veces a causa de las dificultades de interpretación que pueden plantear, y a esto hay que añadir las dificultades inherentes a la localización y acceso a los fondos. El trabajo reivindica el territorio como patrimonio al mismo tiempo que aporta datos inéditos para la historia del puente de Alcántara mediante el análisis de mapas y planos históricos.

\section{SUMMARY}

The study of the construction of the territory and the landscape at different scales has been traditionally based on written documentary sources, and to a lesser extent on the graphic ones. The cartographic sources, as well as paintings, drawings, and photographs have been often relegated to a secondary role, and thus undervalued. This fact is due to the difficulties of interpretation of the cartographic documents, but also to the obstacles to find their location, and even to access to them. This article considers the territory under the scope of the cultural heritage, and collects many historical and unpublished data about the Roman Alcantara Bridge through the analysis of historical maps and plans.
Palabras clave: Paisaje; patrimonio; historia; puentes; cartografía.
Keywords: Landscape; cultural heritage; history; bridges; cartography.

\footnotetext{
(*) Escuela Técnica Superior de Arquitectura y Geodesia - Universidad de Alcalá, (España). Persona de contacto/Corresponding author: pilar.chias@uah.es (P. Chias)
} 
1. EL ESTUDIO DEL PATRIMONIO HISTÓRICO ESPAÑOL A TRAVÉS DEL PROYECTO DE CARTOTECA HISTÓRICA DIGITAL DE ESPAÑA (ANCIENT SPANISH CARTOGRAPHY E-LIBRARY)

Desde tiempo inmemorial, cuando el hombre comenzó a ejercer un control sobre la naturaleza y a tomar posesión del espacio para desarrollar su existencia, por medio de sus obras, configuró el espacio y comenzó a construir el territorio a través de unas tramas de sendas, centuriaciones, bancales, obras de regadío, presas, canales, puentes... El territorio es, pues, un artificio construido por una sucesión de civilizaciones y sociedades y tiene, por tanto, una historia.

Para estudiar la construcción del territorio, la cartografía histórica resulta un instrumento imprescindible. Pero del mismo modo que los cuadros, los dibujos y las fotografías históricas, no se han utilizado tradicionalmente como una fuente fiable de información sobre la historia del territorio y de la ciudad, los mapas no son sino excepcionalmente utilizados porque se han venido considerando como documentos de 'segundo orden', en gran medida debido a las dificultades de interpretación que frecuentemente planteaban (16) a causa de las distintas convenciones que eran empleadas en cada caso por los cartógrafos.

Pero no es ésta la única razón por la cual la cartografía sigue siendo poco utilizada en investigaciones históricas, pues habría que añadir otros problemas relacionados con la dificultad que entraña su localización y consulta directa.

Es evidente que no resulta fácil acceder a un mapa original manuscrito o a uno impreso de grandes dimensiones y pequeña escala, que además suele componerse de varias hojas; también resulta difícil poder leer adecuadamente los símbolos utilizados, las escalas y los textos cuando se manejan copias reducidas o imágenes digitales de baja resolución.

Aunque para los fines propuestos no resulta esencial llegar a tener un conocimiento exhaustivo del contexto de cada mapa para poder interpretarlo adecuadamente (29: 28; 2), sí que es imprescindible contar con un mínimo de conocimientos específicos sobre la teoría de la expresión cartográfica y el dibujo de mapas (sobre proyecciones, simbolización o representación del relieve, por ejemplo), ya que su carencia puede dificultar su lectura y llegar a distorsionar los resultados de las investigaciones (30: 1-10).
Pero es evidente que el trabajo que presentamos no hubiera sido posible sin contar con un conocimiento suficiente o incluso exhaustivo, de los fondos cartográficos disponibles sobre la zona de estudio. Tal ha sido el motivo que nos ha llevado a crear una 'cartoteca digital' en la Universidad de Alcalá. El proyecto, titulado Ancient Spanish Cartography e-Library, tiene como objetivo facilitar el estudio y accesibilidad del patrimonio cartográfico de España a través de Internet, contribuyendo a la difusión de su conocimiento $(11 ; 12)$.

Este proyecto se enmarca dentro de las estrategias que ha establecido el Consejo de Europa sobre las Bibliotecas Digitales (14), a las que considera como un punto de acceso común y pluriligüe al Patrimonio Cultural Europeo, y asume que los mapas históricos constituyen una parte importante del patrimonio cultural de España.

Para definir los contenidos de esta base de datos cartográfica, hemos decidido aplicar el concepto de 'documento cartográfico' en el sentido amplio que le otorgan Harvey (18:7) y Harley y Woodward (17: 1, xvi), que abarca a todo tipo de mapas, planos y cartas náuticas a diferentes escalas (territoriales, urbanas e incluso arquitectónicas), así como cuadros y vistas (20: 18-26), sin ninguna limitación causada por la técnica, las funciones o los orígenes.

En una primera fase hemos restringido los ámbitos temporal y geográfico de los mapas que hemos incluido en la cartoteca digital. En el ámbito temporal incluimos cualquier documento anterior a 1900, fundamentalmente debido a que a lo largo del siglo XX las técnicas y sistemas de producción cartográfica se multiplicaron en muchos sentidos y su estudio debería abordarse independientemente.

Respecto a las limitaciones espaciales, decidimos que la cartoteca debía abarcar cualquier documento que se refiriese al territorio español en la actualidad.

Una última delimitación de esta primera fase de formación de la base de datos afecta a la procedencia de los fondos, que se han localizado en los principales archivos y colecciones de nuestro país, tanto públicos como privados. Obviamente se han respetado todos los derechos y condiciones de consulta que contempla la legislación vigente, citando siempre con precisión la procedencia.

En fases sucesivas se abarcarán otros fondos y se ampliarán tanto el ámbito temporal como el espacial, incluyendo otros territorios. 


\section{LOS INGENIEROS MILITARES Y LA RE- PRESENTACIÓN CIENTÍFICA DEL TE- RRITORIO}

Bajo el reinado del emperador Carlos (1516-1556) se inició una política de fortificación para la defensa de sus vastos territorios, que iba a requerir la adecuada formación de cartógrafos y que daría origen a la fundación de la Escuela de Artillería de Milán en 1543 y al primer diseño de un sistema defensivo para el Imperio.

Impulsó también el primer proyecto de cartografía científica de España encargando en 1551 al Maestro Pedro de Esquivel, profesor de matemáticas en la Universidad de Alcalá y experto en el levantamiento de planos por métodos matemáticos, "pintar la descripción de España" en una serie de mapas detallados de regiones y provincias; un ambicioso proyecto del que comentaría Felipe de Guevara, otro de sus responsables, que "no hubo palma de tierra en toda ella que no sea por el autor vista, andada u hollada, asegurándose de la verdad de todo (en quanto los instrumentos matemáticos dan lugar) por sus propias manos y ojos". La decisión de Felipe II de respaldar los mapas de Esquivel fue inspirada por Felipe de Guevara, que comparó la empresa a la "descripción de todo el Orbe por Marco Agripa".

Los primeros mapas de este proyecto de atlas de España fueron realizados en 1566 con la ayuda del cartógrafo italiano Juan Bautista Gessio y de Diego, hijo de Guevara; a su muerte fueron enviados a Juan de Herrera para que completase la obra, pero nunca se publicaría a pesar del altísimo nivel de los mapas acabados, que se conservan en la Biblioteca del Monasterio de El Escorial (MS. K.1.1) (Figura 1).

La política de construcción de fortificaciones de los territorios del Imperio fue continuada por Felipe II, quien en paralelo, y debido a la necesidad de conseguir una cartografía fiable para el proyecto y construcción de este nuevo sistema defensivo, impulsó la fundación de la Academia de Matemáticas en Madrid en 1582 para nobles y militares, que estaba a cargo de Juan de Herrera y contaba con profesores tan destacados como el cartógrafo portugués Joao Baptista Labanha y el experto tratadista en fortificaciones, maestro mayor de Sevilla e ingeniero del Rey, Cristóbal de Rojas.

Felipe II impulsó otros proyectos cartográficos como el del geógrafo real Jacob van Deventer para Flandes, o las célebres Relaciones Topográficas (1575-78) en las que intervendrían Esquivel, Juan de Ovando,
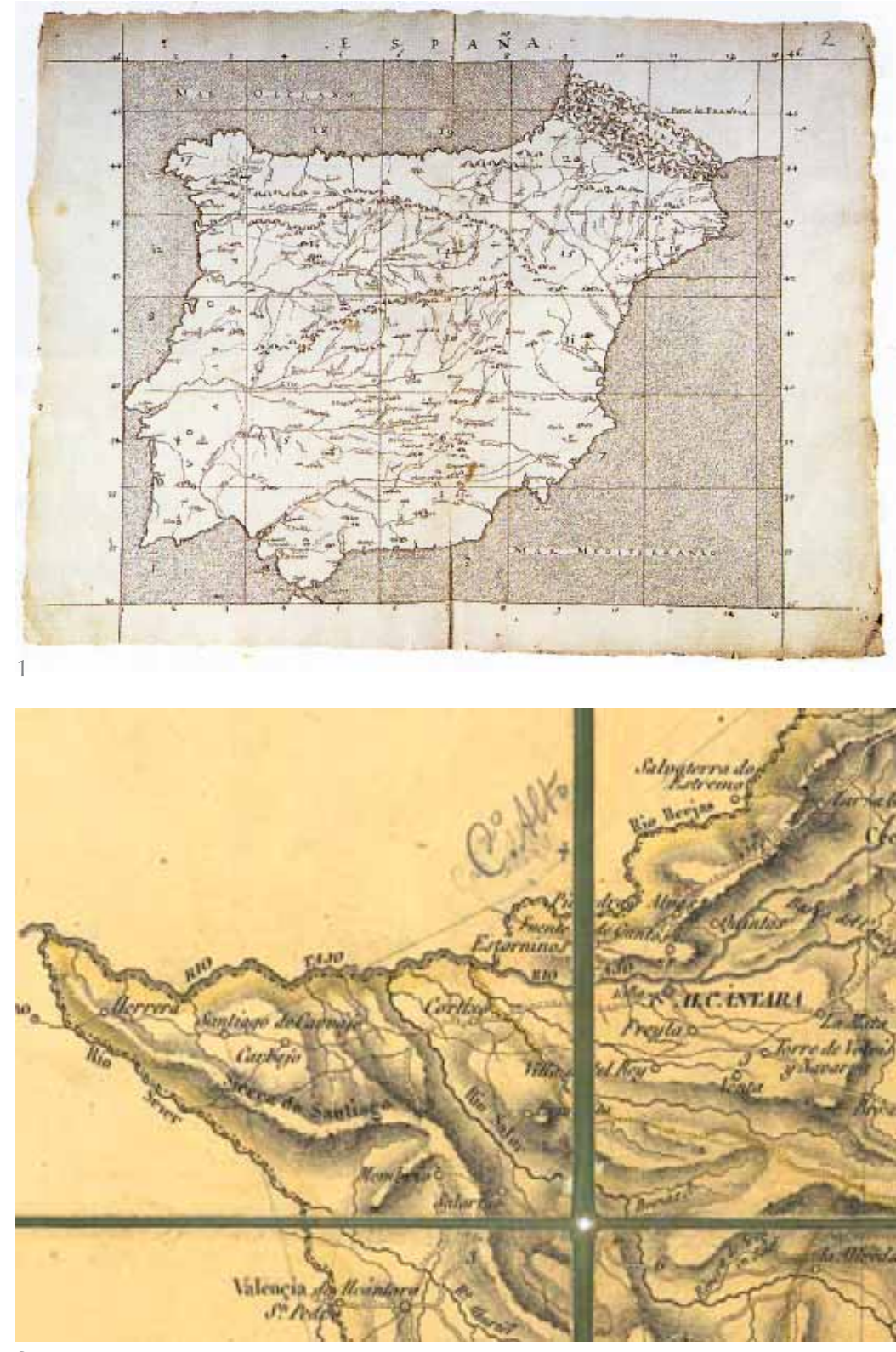

Ambrosio de Morales y Juan López de Velasco, que perseguían reunir pueblo por pueblo información completa, histórica y topográfica, que permitiera completar los mapas de Esquivel. Parte de los municipios abordados en la primera fase pertenecían a la provincia de Cáceres (Pino, El Bronco, Cerezo, Mohedas y Aldeanueva en el obispado de Coria) y llegaron a completarse un total de 35 para la misma provincia en 1578 (6), entre los que lamentablemente no se encuentra Alcántara.

La crisis sucesoria que se produjo en el reino de Portugal al morir sin descendientes el cardenal Enrique I el Casto, provocó una acción militar de las tropas españolas para defender los derechos de Felipe II a la corona; ésta culminaría con la unión temporal del reino vecino al de España entre 1581 y 1640, sucediéndose un periodo de relativa estabilidad fronteriza. Curiosamente esta
1. Pedro de Esquivel, Mapa de España y Portugal (1566-1580) del primer proyecto de cartografía científica de España, Biblioteca del Monasterio de El Escorial, MS. K.1.1. (San Lorenzo de El Escorial, Madrid, España)

2. A.H. Dufour, Mapa de Extremadura con las nuevas divisiones (París, 1849). Detalle de las proximidades de Alcántara en las que se sitúa erróneamente el símbolo y el año de la batalla de Alcántara. Instituto Geográfico Nacional (Madrid, España). 
acción tuvo lugar en la localidad portuguesa de Alcântara, freguesía próxima a Lisboa y escenario de la importante batalla librada en 1580. Resulta sorprendente el hecho de que las dos poblaciones homónimas dieran origen a confusiones como la que refleja el plano de Dufour (1849) en la que se sitúa erróneamente la batalla en las proximidades de la Alcántara extremeña (Figura 2).

Por otra parte, la centralidad establecida por el rey en torno a Madrid, El Escorial, Toledo y Aranjuez, y las obras que en estos lugares fue acometiendo, dieron una cierta preponderancia a los proyectos de obras hidráulicas en el Tajo; la anexión de Portugal situó en primer plano la idea de su navegabilidad entre Toledo y Lisboa, según proyecto del ingeniero italiano Juan Bautista Antonelli.

En el verano de 1581 se acometieron con celeridad las obras del primer tramo entre Abrantes y Alcántara, obras que quedaron concluidas el 27 de octubre de 1582, incluyendo los caminos de sirga "abiertos en peña viva" (según escribió Marco Artu en el reconocimiento que hizo en 1829 para el proyecto de Cabanes), y en mayo de 1583 está documentado un movimiento de tropas por el río hacia Lisboa. Aunque la navegación completa fue posible desde 1587, lamentablemente no hubo apenas actividad comercial y esta circunstancia, unida a otras dificultades coyunturales y al fallecimiento de Antonelli en 1588, debió llevar a la paralización del tráfico hacia 1594 y al abandono de las obras. Sin embargo, la mayoría se conservaban en buen estado en 1641, y así figuran en el mapa de Carduchi, como veremos más adelante.

Durante este periodo de relativa tranquilidad respecto a Portugal, Felipe III creó en 1601 la figura del Ingeniero Mayor de las Fortificaciones: el primero fue Tiburzio Spannocchi, a la vez que Leonardo Turriano era nombrado para los reinos de Portugal; asimismo por la ley de 2 de febrero de 1612 quedaron reguladas las facultades y privilegios de los ingenieros reales. Tampoco se desatendió su formación, nombrándose al Cosmógrafo Mayor Andrés García de Céspedes maestro de su Real Escuela de Matemáticas, ciencia básica en la que habían de formarse los ingenieros de fortificación y base común a la arquitectura civil y militar.

Comenzó entonces un periodo en el que se dictaron numerosas leyes y normas sobre las fortificaciones a la vez que se acometían trabajos de modernización (5), abordándose simultáneamente obras en aqueIlas plazas que históricamente estaban más expuestas, como era el caso de Alcántara.
Ya bajo el reinado de Felipe IV, en 1641 fue nombrado el jesuita Jean Charles de la Faille Cosmógrafo Mayor de las Indias y consejero militar del rey en la defensa de plazas fuertes, a la vez que le encargaba la planificación de la guerra con Portugal.

A pesar de las constantes guerras con Francia (1635-1659), este país sirvió de referencia en muchos aspectos a los gobernantes españoles y el Conde-Duque de Olivares, en un afán de emular las políticas de obras de Richelieu, impulsó los proyectos de construcción de canales y la navegación de varios ríos, retomando entre ellos el del Tajo a raíz de la guerra con Portugal en 1640 y a causa del elevado coste que suponía el transporte de víveres y municiones. Para realizar el reconocimiento del estado de las obras y de la posibilidad de replantear la navegación del río se recurrió a Luis Carducci o Carduchi, un arquitecto militar e hidráulico de la familia de los pintores que había venido a España en época de Felipe II y que se había formado en la Academia Real de Madrid (Figura 3).

En el tercer cuarto del siglo XVII y ya bajo el reinado de Carlos II, el último rey Austria, aún continuó esta política de refuerzo de las fortificaciones, como demuestran los trabajos de los ingenieros Fernando y Carlos de Gruneberg, que fueron enviados desde Flandes a la frontera portuguesa en 1670.

La obra de Tomás Vicente Tosca puede considerarse como el resumen de lo que fuera la ciencia de la fortificación a finales del siglo XVII. Dedicó el tomo $\mathrm{V}$ de su Compendio Mathematico (1705-1715, reed. $1727,1757)$ a la arquitectura civil, el arte de la montea y la cantería, la arquitectura militar, la pirotecnia y la artillería. Decía que "el ingeniero ha de tener a lo menos una mediana noticia de la Geometría" (p. 279), y sobre el dibujo, explicaba que era esencial para la estrategia y la descripción. Como recomendara Vitrubio, el ingeniero debía saber:

- Hacer mapas de un territorio (icnografia, también usado para la planta de una fortaleza).

- Formar mapas parciales (corografía).

- Delinear las fortificaciones sobre el terreno, para lo que debía dominar los sistemas de medición del terreno, necesarios para trazar la planta de la fortificación y para plantar las estacas que marcaban el trazado, con los ángulos precisos para que se construyera conforme a la traza. También tenía que saber manejar los instrumentos, aunque limitados a la escuadra, a dos palos rectos, a los piquetes $y$ 
al cordel dividido en pies, y remite para más precisiones a su Geometría práctica (Tosca 1705, 374). Además, redujo todas las escalas (verga, paso andante, paso geométrico, pie, braza, cana, vara, codo, palmo, trabuco) a pies geométricos o valencianos.

- La escenografía (perspectiva) no tenía obligación de hacerla el ingeniero, a quien competían la icnografía y la ortografía. Además, como la escenografía no se podía medir, no tenía interés para el diseño de fortificaciones.

- Sobre la importancia de la perspectiva "que sin guardar el rigor de las leyes ópticas, es muy proporcionada para las Fortificaciones, por lo que se llama Perspectiva Cavallera Militar, y también Paralela, por formarse de solas líneas paralelas: con esta se conservan en la descripción las propias dimensiones Geométricas de todas las partes de una Fortaleza" (p. 319). Explicaba cómo hacerla, y su éxito radicaba en que se podían medir las tres dimensiones, perfectamente definidas geométricamente.

- Y respecto a las escalas, "el Ingeniero, en cualquier planta, o descripción, debe poner el pitipié, el cual es una línea dividida en muchas partes iguales que representan las medidas de la planta delineada." (p. 289).

En 1710 fue nombrado el teniente general flamenco Próspero de Verboom Ingeniero General de los Ejércitos y Plazas de España y demás dominios de la Monarquía, con el encargo de reorganizar el cuerpo de ingenieros de un modo similar al creado en Francia por el mariscal Vauban. Un año después creó el Cuerpo de Ingenieros, para cuyas filas reclutaría inicialmente extranjeros formados en Bruselas.

En 1718 se promulgó la primera Ordenanza del Cuerpo de Ingenieros por la cual habrían de encargarse de "la formación de Mapas, o Cartas Geográficas de Provincias, con observaciones y notas sobre los ríos que se pudieran hacer navegables, aguas para Molinos, Batanes, Riegos, y otras diversas diligencias dirigidas al beneficio universal de los Pueblos; y asimismo el reconocimiento y formación de Planos, y relaciones de Plazas, Puertos de Mar, Bahías y Costas, y de los reparos y nuevas obras que se necesitasen, con el tanteo de su coste [...]". (28, art. 25 p. 767)

También se articulaban las normas a seguir en la elaboración de mapas, aunque el método se dejaba a elección del ingeniero "por ser de sobra conocidos por los Ingenieros, dependiendo de las condiciones del terreno y aparatos disponibles" (27). Los métodos a emplear serían los de radiación en vuelta de

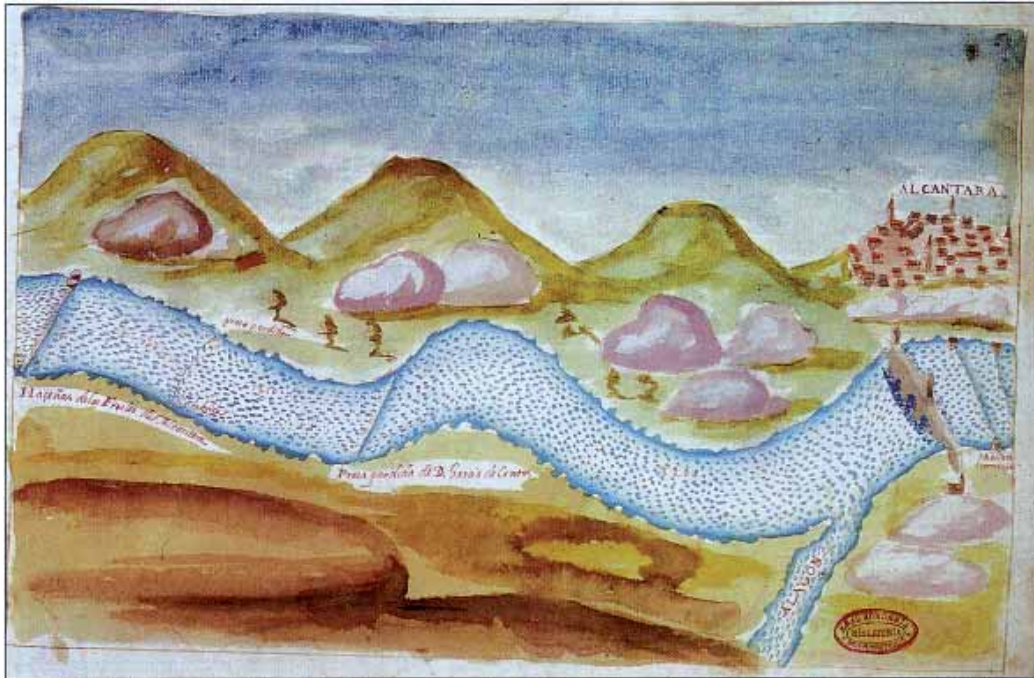

horizonte, intersección desde los extremos de una base conocida, triangulación gráfica y medición indirecta de distancias y alturas inaccesibles por triángulos semejantes, entre otros. Y los aparatos disponibles eran, básicamente, el nivel de agua, la rueda contadora de distancias, el podómetro o cuenta pasos, la cadena de agrimensor, la plancheta, los teodolitos para la medición de ángulos horizontales y verticales, y la brújula.

Por otra parte, Verboom fue requerido por el rey en 1712 para realizar un informe sobre el estado de las fortificaciones del Reino, y tras visitarlas convenientemente concluyó que presentaban grandes deficiencias. Con tal motivo, en 1720 se fundó la Real y Militar Academia de Matemáticas y Fortificación de Barcelona, cuyos estudios se basaron en un principio en las enseñanzas de Tosca, incluyendo Aritmética, Geometría, Trigonometría, Topografía y Esfera, además de los preceptivos conocimientos de artillería, fortificación, mecánica hidráulica o construcción, entre otras materias; se enseñaba a construir cartas geográficas y a proyectar edificios civiles y militares, pero respecto al dibujo se fue prescindiendo gradualmente de la Escenographia o perspectiva porque a criterio de muchos, como Cassani, "sólo servía de curiosidad" (9); se redujo el uso de la Ortographia y se centró la atención en la Ichnografia por considerarse que era la que debía dominar el arquitecto militar. La Academia fue dirigida por ingenieros militares tan eminentes como Pedro de Lucuze o Mateo Calabro.

El 3 de julio de 1737, y a instancias del duque de Montemayor, se creó la Real Junta de Fortificación con el cometido de examinar todos los proyectos de defensa; como consecuencia, se vieron incrementados los presupuestos para la reparación de plazas fuertes, en los que Extremadura no resultaría especialmente beneficiada.
3. Carduchi, L. Chorografia del Rio Tajo...1641. Real Academia de la Historia (Madrid, España). Representa la confluencia del rio Alagón, Alcántara y el puente. 

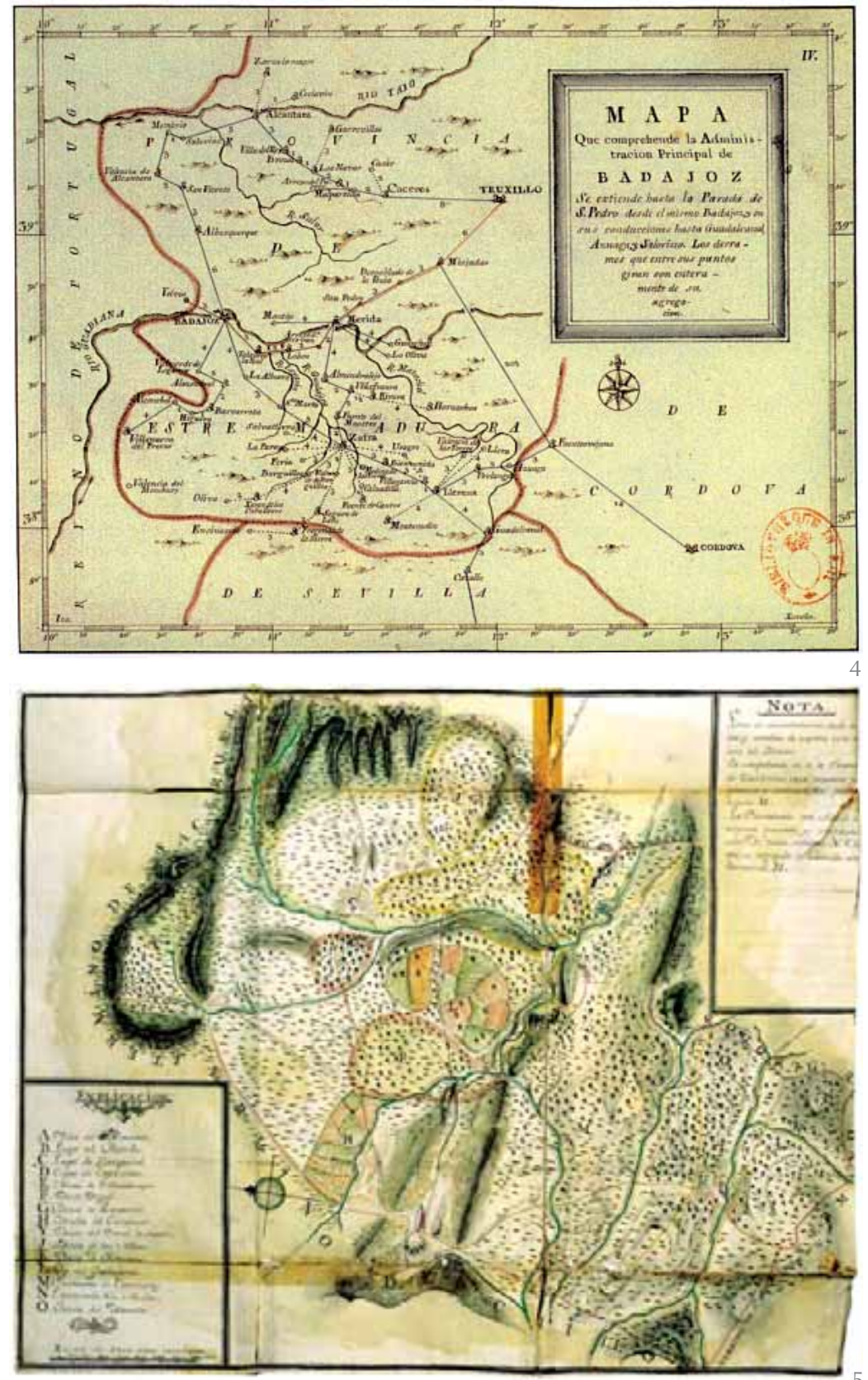

4. Francisco de Yta y Juan Victoriano Xareño, Mapa que comprehende la Administración Principal de Badajoz; incluido con el número IV en el Atlas Geográfico de Correos, Postas y Estafetas de la Península de España. Madrid, 1789-1790. Bibliothèque nationale de France (París, Francia).

5. Uno de los planos más interesantes del Catastro de Ensenada corresponde al municipio de Almadén (Archivo Histórico Provincial de Ciudad Real). En concreto, las respuestas correspondientes a Alcántara se encuentran en el Archivo General de Simancas, pero carecen de planos o imágenes, y apenas tienen un pequeño croquis de los límites municipales en la página 4 .

En definitiva, fue este un periodo especialmente fructífero en la realización de dibujos y atlas, resultado en su mayoría de las continuas guerras.

Ya bajo el reinado de Carlos III, en 1774, se reestructuró de nuevo el Cuerpo y se estableció una división en tres ramos que habría de mantenerse hasta 1803:

El de las Academias Militares; la de Barcelona se mantendría bajo la dirección de Lucuze.

El de los Caminos, Puentes, Edificios de Arquitectura Civil, Canales de Riego y Navegación, que habrían de estar dirigidos por Francisco Sabatini.

Y el ramo de Plazas y Fortificaciones del
También durante el reinado de Carlos III se dictaron las Ordenanzas del Cuerpo de Ingenieros de Marina (1772), asignándoles las competencias de obras portuarias (1782) sin que por ello dejasen de intervenir otros ingenieros. También promulgó un Real Decreto en 1762 "Expedido para hacer caminos rectos y sólidos en España" y una Real Orden de 22 de octubre de 1768 con las nuevas ordenanzas para ingenieros, en la que se especificaba que el método de levantamiento seguía siendo responsabilidad del ingeniero encargado de redactar la cartografía, se disponía que los signos convencionales habían de ser los indicados por el ingeniero general (en un intento de homogeneizar la simbolización cartográfica, como ya se había hecho en Francia), que de cada plano original habían de hacerse tres copias (para el capitán general, para el ingeniero general y para el Archivo de la Secretaría de Guerra), y qué planos habían de acompañarse de las correspondientes memorias.

Precisamente a Lucuze se deben las primeras normas sobre cómo dibujar planos o ichnographias, perfiles u ortographias y la elevación o escenographia; y sobre la escala, para la que adoptó como medida base la "Vara de Castilla del Marco de Burgos, que consta de tres pies, cada pie de doce pulgadas, y cada pulgada de doce líneas." (22: 17). Estableció, asimismo, la equivalencia con las medidas europeas (23).

Pero las iniciativas adoptadas por los reyes españoles no fueron acompañadas de la inversión necesaria (muy superior a la requerida en Francia a causa de la orografía y la hidrografía de nuestro país) y no pudieron superar a las del vecino reino ni en materia de regulación de los ingenieros del rey ni de las inversiones en obras públicas, que fueran impulsadas tanto por Mazarino como por Colbert. Reino, que quedó bajo la dirección de Silvestre Abarca.
El estado de las comunicaciones en nuestro país era muy diferente, como destacaría Bernardo Ward en su Proyecto económico de 1762, y cuyas deficiencias se reflejan claramente en la cartografía de la época como en el mapa de correos manuscrito de Yta y Xareño (1789-1790), (Figura 4) siendo la más fiable la procedente de fuentes militares, e incluso la cartografía de escala menor realizada en imprentas del extranjero, especialmente en Francia y en los Países Bajos.

Y aunque Jorge Juan había redactado en 1751 su Método de levantar y dirigir el mapa o plano general de España, con reflexiones a las dificultades que pueden ofrecerse, Jovellanos se lamentaba de la situación con comentarios como: "[Jóvenes], 

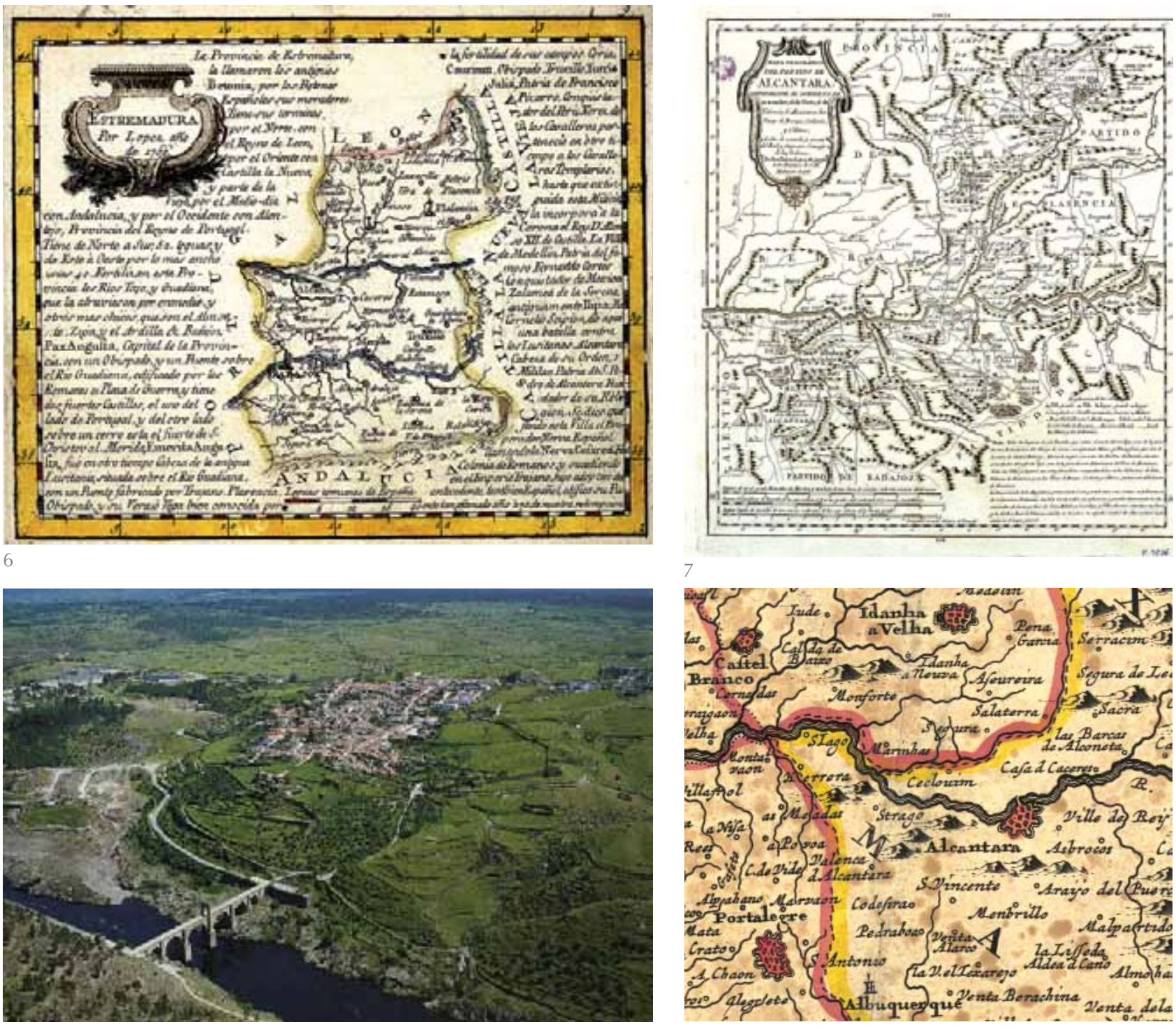

¿Cuándo os verán mis ojos, precedidos de vuestros maestros, trepar por esas cumbres que nos rodean, con el teodolito al ojo y el compás a mano, medir en vastos triángulos el territorio? ¿Cuándo os veré yo reducir este trabajo a una breve y exactísima carta topográfica, que multiplicada por el buril, difunda por todas partes, con la imagen de nuestra patria, el más ilustre testimonio del amor que le profesáis?".

En general, el conocimiento que nuestros gobernantes tenían del país era muy deficiente, y esta necesidad de conocer adecuadamente la estructura de los territorios de la corona de España había impulsado proyectos ilustrados tan memorables como el del Catastro de Ensenada, puesto en marcha por un Real Decreto de Fernando VI de 10 de octubre de 1749 e iniciado en 1750 , como paso previo a una reforma fiscal y basado en una campaña exhaustiva de encuestas e informes aportados por las autoridades de las distintas poblaciones. (Figura 5)
Otro de los empeños del marqués de la Ensenada era paliar la falta de cartografía: "No hay cartas puntuales del Reyno y de sus provincias; no hay quien las sepa grabar, ni tenemos otras que las imperfectas que vienen de Francia y Holanda" (informe al rey, de enero de 1748). Para desarrollar el proyecto intentó inicialmente traer a España a un técnico francés, pero ante la oposición del rey de Francia optó por enviar a París como becario durante nueve años a Tomás López, para que a su vuelta pusiese en práctica lo que había aprendido.

Sin embargo, ante el fracaso final del proyecto y conocedor del acuciante problema de desinformación geográfica que existía en España, Tomás López emprendió por su cuenta la confección de una cartografía general basada en encuestas. De la gran colección de mapas que grabaron él y sus sucesores en su empresa familiar, merece comentarse que empezaron a representar los territorios extremeños en 1756 (Figura 6). Este ilustre cartógrafo fue un entusiasta
6. Tomás López, Extremadura Este mapa, impreso y coloreado, se publicó en el Atlas Geographico del Reyno de España e Islas Adjacentes, Con una breve Descripción de sus Provincias. Madrid, 1757, con el número 9 Biblioteca Nacional de España (Madrid, España).

Tomás López, Mapa geográfico del partido de Alcántara (1785), Biblioteca Nacional de España (Madrid, España).

8. Vista aérea de la villa de Alcántara y el puente romano en la actualidad, que muestra clara mente el carácter estratégico de ambos, Archivo Iberdrola.

9. La plaza fortificada de Alcántara en Dankerts, I. Regnum Castellae Novae, Andalusiae, Granadae, et Algarbiae, nec non Maxime Partis Portugalliae, et Extremadurae Amsterdam, 1701 1713; detalle, Instituto Geográfico Nacional (Madrid, España). 


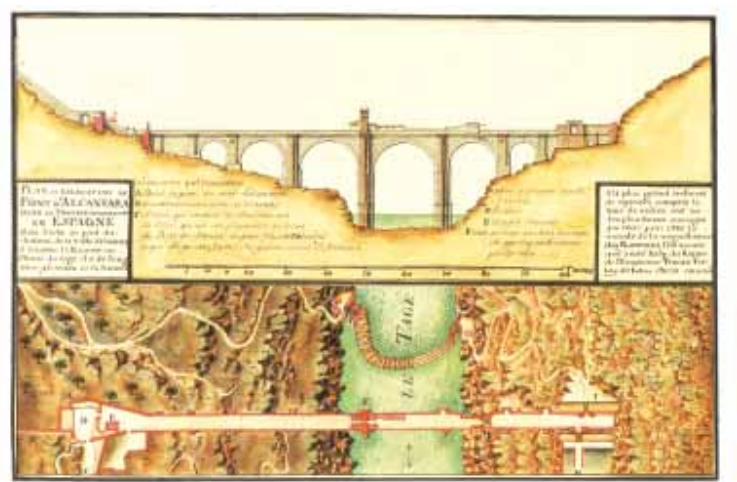

10

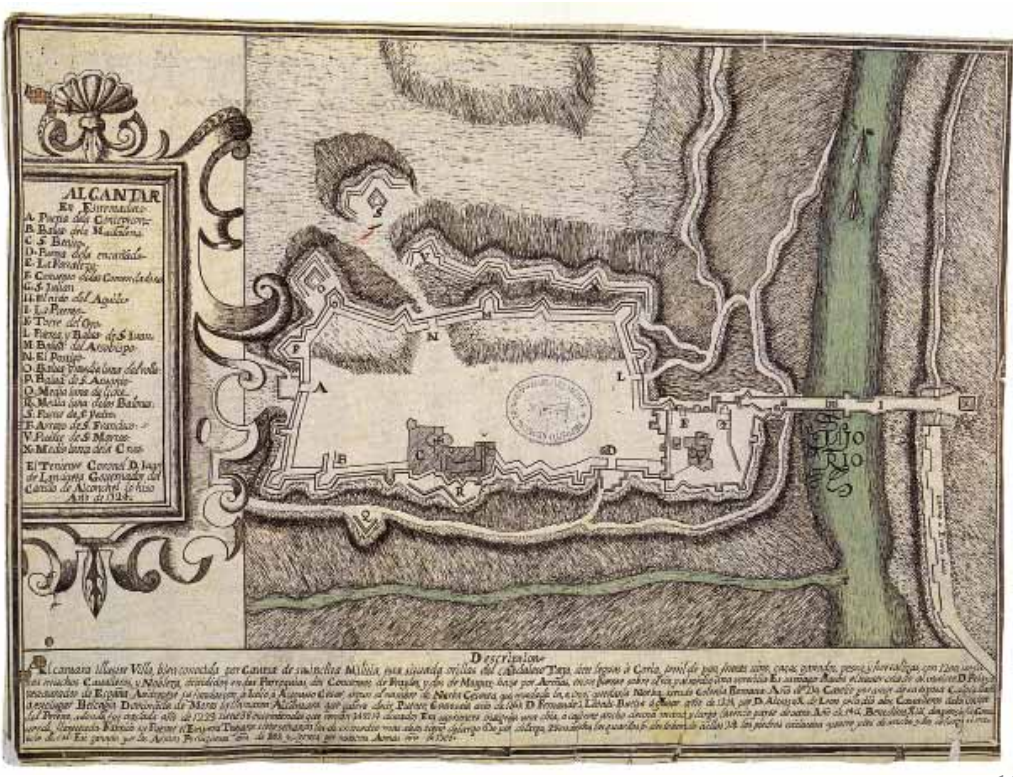

12

10 y 11. Anónimo francés, Plan de la Ville et Château d'Alcantara dans la Province d'Extremadura en Espagne y Plan et Elevation du Pont d'Alcantara pertenecientes al Massé,1705; hojas 37 y 38. Archives du Génie, Service Historique de la Défense (Vincennes, París). Representa el relieve por sombreado.

12. Juan de Landaeta, Alcantar [sic] en Estremadura (1724). Obsérvese la representación del relieve mediante una aproximación rudimentaria al método de las normales. Archivo General Militar de Madrid, Instituto de Historia y Cultura Militar (Madrid, España).

13 y 14. Carlos Geisto de Gendia, [Proyecto de reconstrucción del puente de Alcántara][1750]. Planos de la reconstrucción propuesta y maqueta del estado del puente. Ministerio de Cultura. Archivo Histórico Nacional (Madrid, España). compilador que no hizo nunca trabajos de campo; desde su oficina en Madrid solicitó a los párrocos planos de todas las villas y ciudades de España para reelaborarlos en un atlas, citando siempre detalladamente sus fuentes con gran honradez; y el éxito fue tal que no sólo realizó varias ediciones, sino incluso varios atlas. Sus mapas son de una gran belleza y de escasa precisión, y aunque en algunos muestra tener ciertos conocimientos de cartografía científica, la mayoría de ellos podrían calificarse de "mapas de experiencia" (20: 104-105).

Dedicó muchos a Extremadura en su conjunto o en parte (Extremadura de 1766, 1790 y 1798; sierras de Guadalupe de 1781, partido de Mérida de 1783, partido de Jerez de los Caballeros de 1784, partido de Llerena de 1785, partido de Villanueva de la Serena de 1786, Badajoz de 1794, obispado de Plasencia de 1797), entre los que no podía faltar el Mapa geográfico del Partido de Alcántara (1785) (Figura 7), en el que aparece la ciudad como "villa grande" e importante cruce de caminos y travesía obligada del Tajo.

Su labor cartográfica fue continuada por sus hijos en sus talleres de Madrid, prestan-
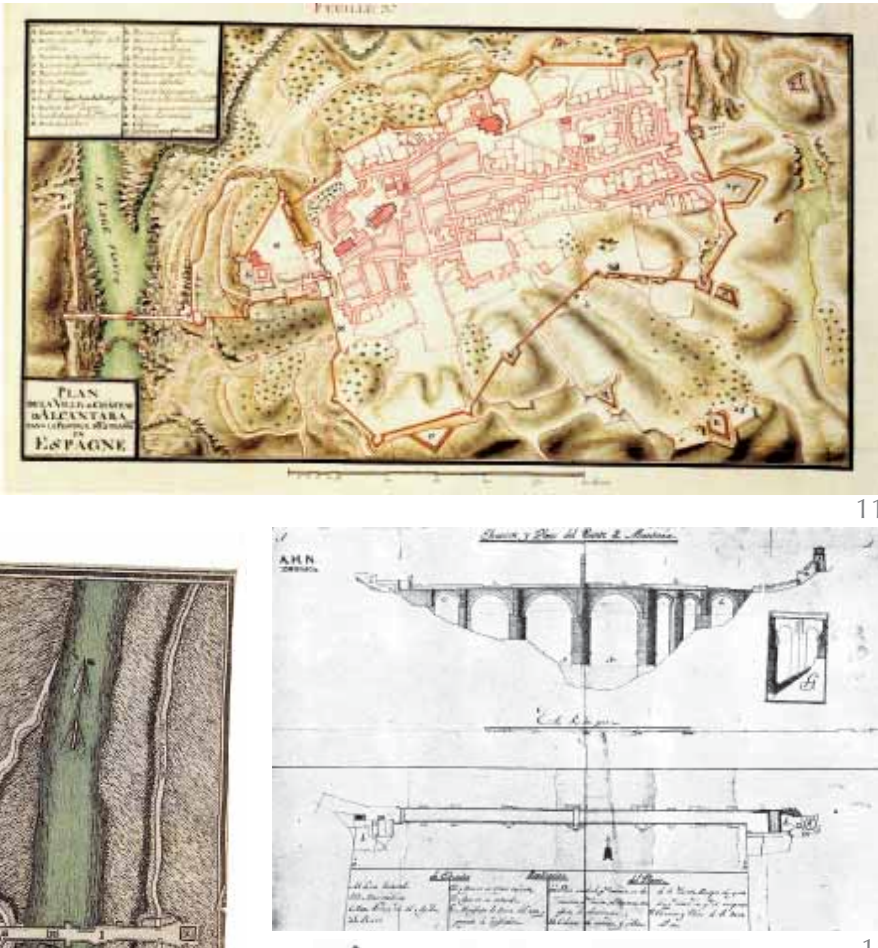

13

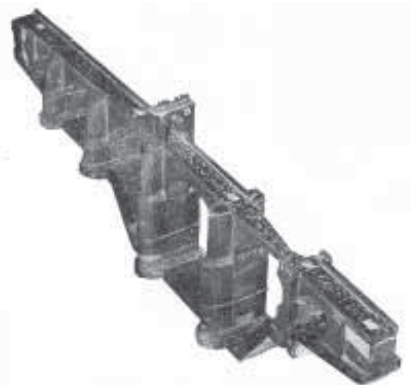

do atención a este ámbito geográfico con mapas temáticos como el dedicado al Conde de Floridablanca y titulado Mapa de la Lusitania antigua con su correspondencia moderna (española y portuguesa) (1789), en el que aparece en lugar destacado Alcántara con el nombre de Norba Cesarina.

\section{ALCÁNTARA, UNA POSICIÓN ESTRATÉGICA}

La situación geográfica de la villa de Alcántara, sobre un promontorio capaz de vigilar el camino procedente de Portugal desde el norte, y del propio puente de Alcántara a sus pies sobre el Tajo, único paso disponible en este tramo del río en cualquier época del año, hacía que esta plaza fuese especialmente importante para cortar los posibles avances de ejércitos procedentes de Portugal (Figura 8). De hecho, aparece simbolizada como una fortificación importante (15: 530) en numerosos mapas generales y parciales desde el siglo XVII (Figura 9).

Del interés suscitado por la plaza queda constancia en numerosos documentos históricos que detallan con mayor o menor fortuna sus características defensivas. 

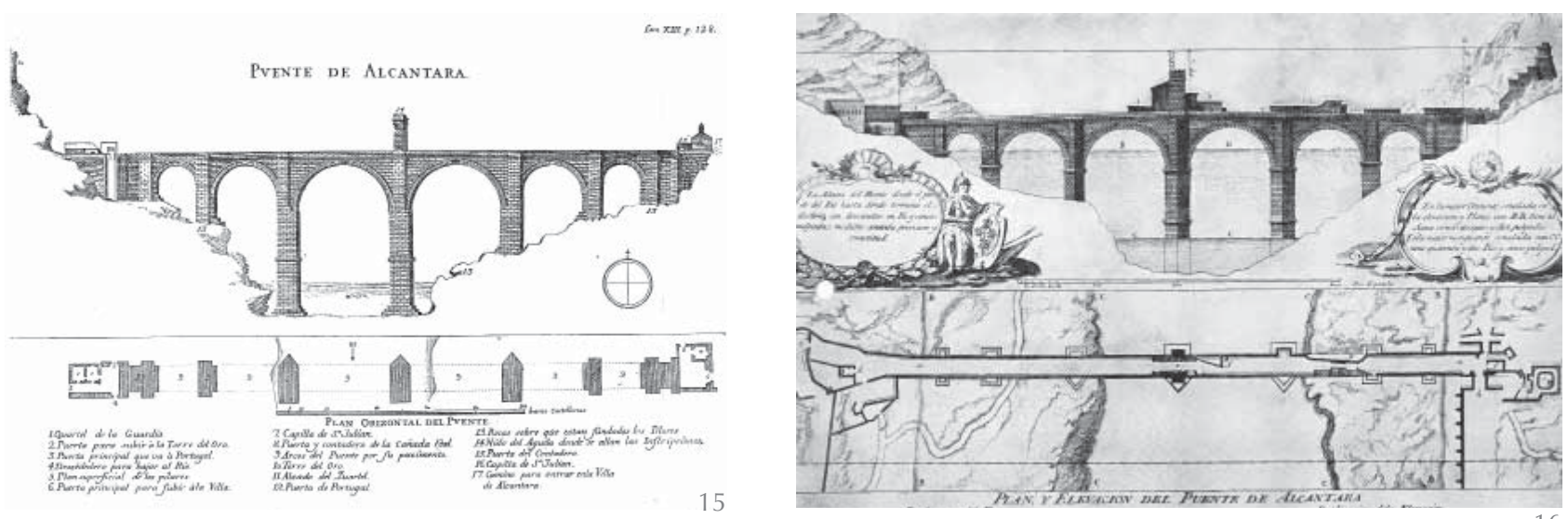

Resulta muy interesante comparar los dibujos manuscritos contenidos en el Atlas Massé (1705) (Figuras 10 y 11) con el también manuscrito plano de Juan de Landaeta (1724) (Figura 12), centrados ambos en el mismo ámbito geográfico.

El anónimo francés describe con detalle hasta el interior de la población, siguiendo las directrices dadas por el rey Enrique IV en el Grand Réglement de Sully (1604) (BNF Manuscrits français, collection de Cangé fol. 114, y Archives du Ministère des Affaires étrangères, France 766, fols. 10-13), en el que se especificaba que los ingenieros del rey debían hacer en cada provincia del reino mapas anotando "los puentes apropiados para pasar la artillería, los vados o pasos más fáciles de atravesar, los ríos, los caminos más o manos malos" y "el nombre de todas las ciudades, plazas y castillos que podrían aguantar el cañón si fueran atacados" (26).

Por su parte, el plano de Landaeta se centra especialmente en las defensas y los postigos de Alcántara, representando únicamente en su interior las construcciones de San Benito y del convento de las Comendadoras. Sin embargo, en la leyenda describe ciertos hechos históricos como su origen como colonia romana (Norba Cesarea), luego dominada por los árabes y renombrada Alcantara en mención del puente. Reconquistada sucesivas veces, la definitiva fue en 1214 por Alfonso X de León. Posteriormente, fue ganada por las armas portuguesas en 1705 y recuperada al año siguiente por la españolas, aunque debieron sucederse las escaramuzas en los años siguientes. De ahí el interés renovado por la plaza.

En la segunda mitad del siglo XVIII se Ilevaron a cabo otros estudios sobre el estado de conservación del puente como los realizados por Carlos Geisto de Gendia, que incluyen además de los planos una maqueta. (Figura 13y14) La fábrica mostraba entonces los graves daños que en el tablero había causado una mina portuguesa en 1707 , y que se
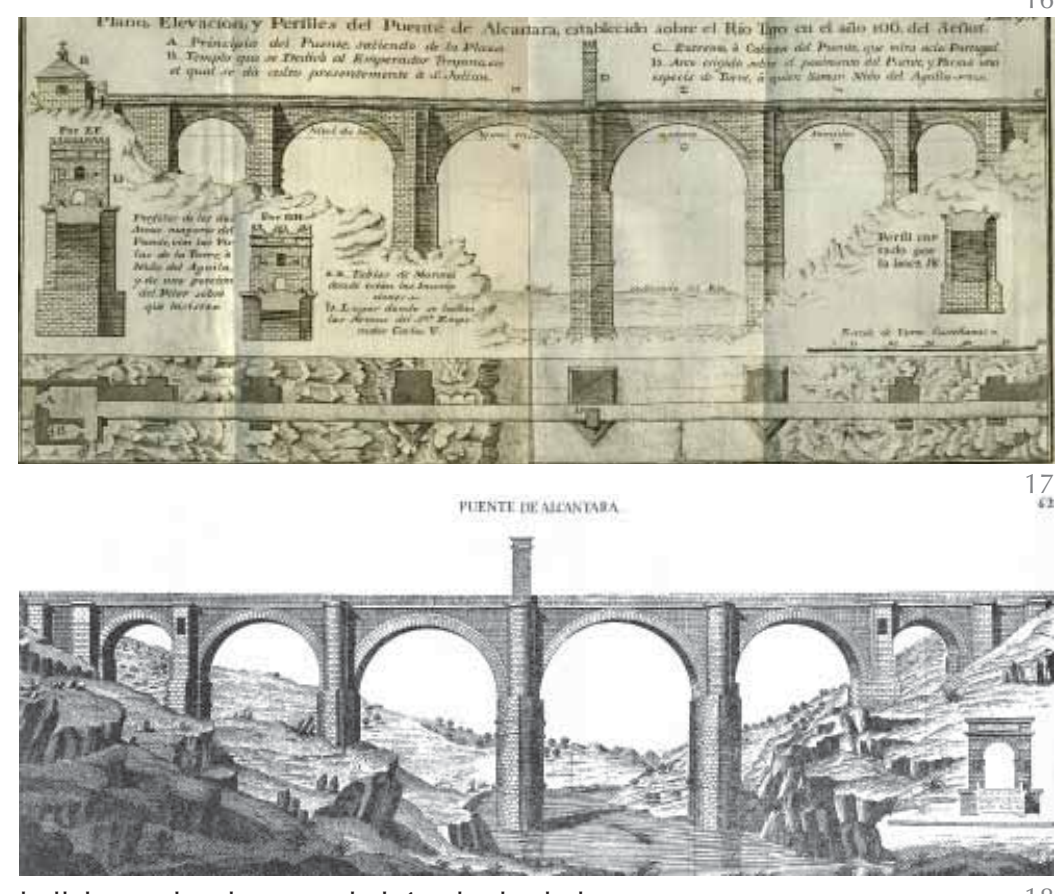

hallaban sobre la segunda bóveda desde la orilla meridional del Tajo como consecuencia de la desaparición de una parte de su riñón izquierdo en el alzado de aguas arriba. Se habíaperdido parte del pretil y el paso útil se veía considerable y peligrosamente reducido. La solución que se planteaba entonces era técnicamente muy inferior a la de los ingenieros romanos, ya que se proponía construir un par de bóvedas gemelas de cañón y pequeña luz en sustitución de la original. El proyecto no llegó a realizarse.

Una imagen ideal del puente es la que dibujó Sebastián de Araújo en 1756 para la España Sagrada del P. Flórez (Figura 15), en la que se muestra el alzado aguas abajo y la planta, incluyendo detalles como el remate que entonces tenía el templete de Cayo Lácer (convertido en la capilla de San Julián) o la construcción del lado de Portugal (septentrional) con el descendedero al río y el acceso a la Torre del Oro.

El siguiente documento gráfico que se ha conservado sobre el puente se trata de una planta y un alzado aguas arriba que fueron 

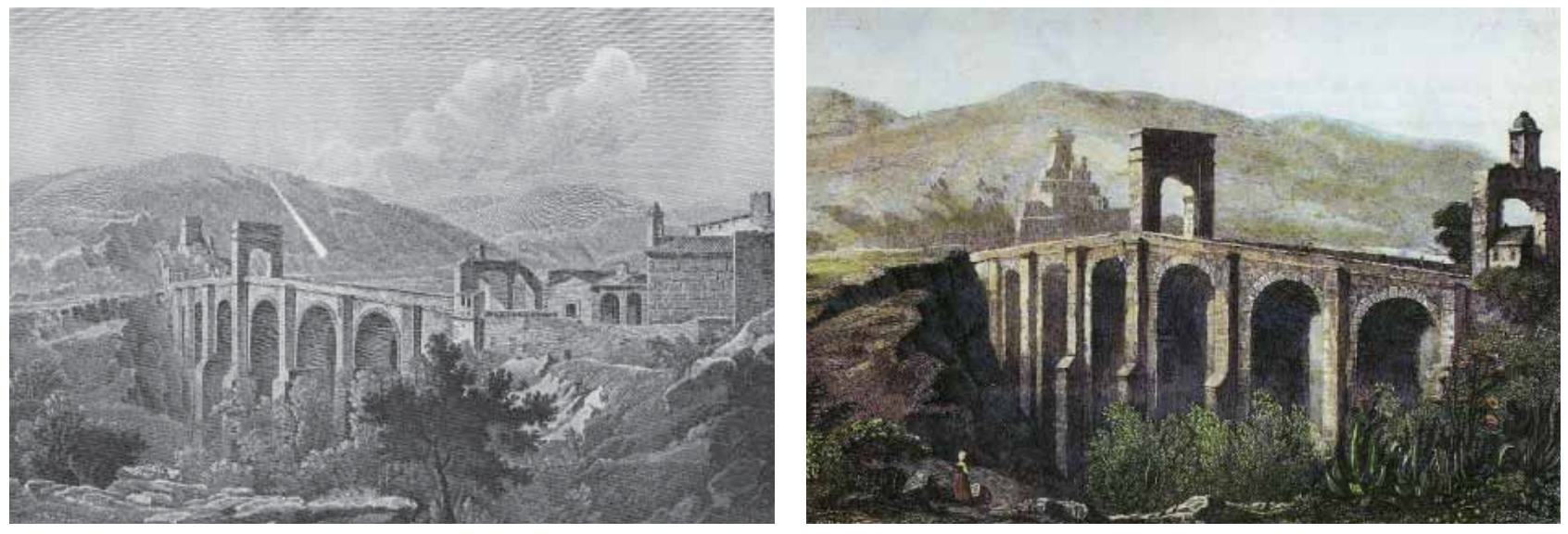

9
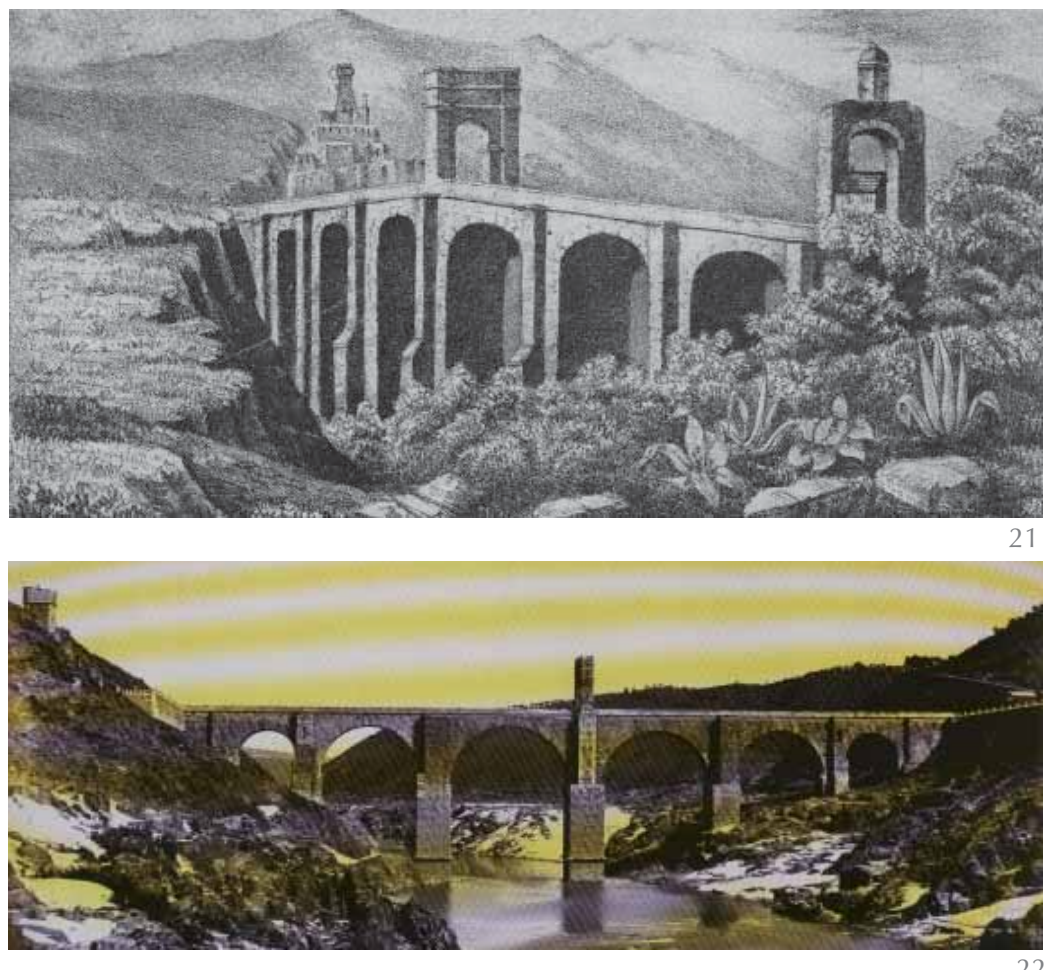

19. Robert de Launay (grabador), $1^{\text {a }}$ Vista del Puente de Alcántara; en Laborde, A. Voyage pittoresque et historique de l'Espagne, 1811 , t. 1, parte 2, p. 116, estampa 61, Biblioteca Nacional de España (Madrid, España).

20. Gaucherel-Le Maître, litografía de mediados del siglo XIX que muestra una vista del puente de Alcántara, como una variante del grabado de Laborde; incluye un personaje.

21. Viu, J. de Antigüedades de Extremadura, 1852. Reproduce otra variante de la vista del puente de Laborde en la que el personaje ha desaparecido; obsérvense las variaciones en la representación de la topografía y en la vegetación

22. J. Laurent, Cáceres, Puente de Alcántara.

realizados por Esteban Rodríguez para el libro de Alonso de Torres y Tapia titulado Crónica de la Orden de Caballería de Alcántara (1763).(Figura 16) Este plano muestra con precisión la altura máxima de las crecidas del Tajo y la altura del agua en época de estiaje. Reproduce los mismos daños que la maqueta de Geisto de Gendia, pero aporta mucha más información sobre las construcciones defensivas, las baterías y los cuerpos de guardia "modernos" que tenía entonces adosado el puente romano, destacando en particular las que se apoyaban sobre el arco de triunfo central. A diferencia de los otros dos planos del puente citados, éste se interesa por el entorno inmediato, y muestra la escarpada topografía de las márgenes del río y los caminos que conducían al puente.

De 1769 data otro de los planos más hermosos del puente de Alcántara: el que secciones transversales del puente y de las pilas y estribos, además de información sobre la fábrica de sillería del alzado de aguas arriba. Sin embargo, la descripción que hace del arco de triunfo situado sobre la pila central, con un vano claramente más pequeño de lo que es en realidad, hace dudar de la veracidad del resto de los datos que aporta.

El hecho de que el puente de Alcántara volviese a figurar en un libro una década más tarde es una clara muestra del interés que ya entonces suscitaba y del valor que se le concedía como elemento singular dentro de los hitos culturales de nuestro país; en este caso, se trata de una vista incluida en un libro de viajes, el Viage de España de Antonio Ponz (1776).(Figura 18) Las cualidades de la vista respecto al punto de vista elegido (centrado respecto al cauce y a la altura de la línea de imposta), y la ausencia de deterioro en las fábricas, proporcionan una descripción idealizada de la obra, a la vez que transmiten la potencia de su morfología y la esbeltez de sus proporciones. realizara Sanchez Taramás para su Tratado de fortificación (Figura 17), que incluye
También el pintor Mariano Sánchez realizó una serie de ciento dieciocho cuadros de ciudades y puertos españoles para la colección real que hoy se conservan repartidos entre el Museo del Prado y Patrimonio Nacional. Estas vistas, a imitación de las series realizadas por Vernet o por Alexandre Jean Noël y François Allis sobre puertos y ciudades francesas, tenían la particularidad de haber sido realizadas sobre el terreno empleando una cámara oscura y mostrando un gran interés por la precisión y la objetividad, lo que les daba una utilidad particular como representación topográfica. Entre la serie que realizara en 1792 se halla una vista del puente de Alcántara, y otra del de Mérida.

La moda de las vistas se extendió rápidamente por Europa a lo largo de la primera mitad del siglo XIX, y como consecuencia comenzaron a comercializarse y a circular 

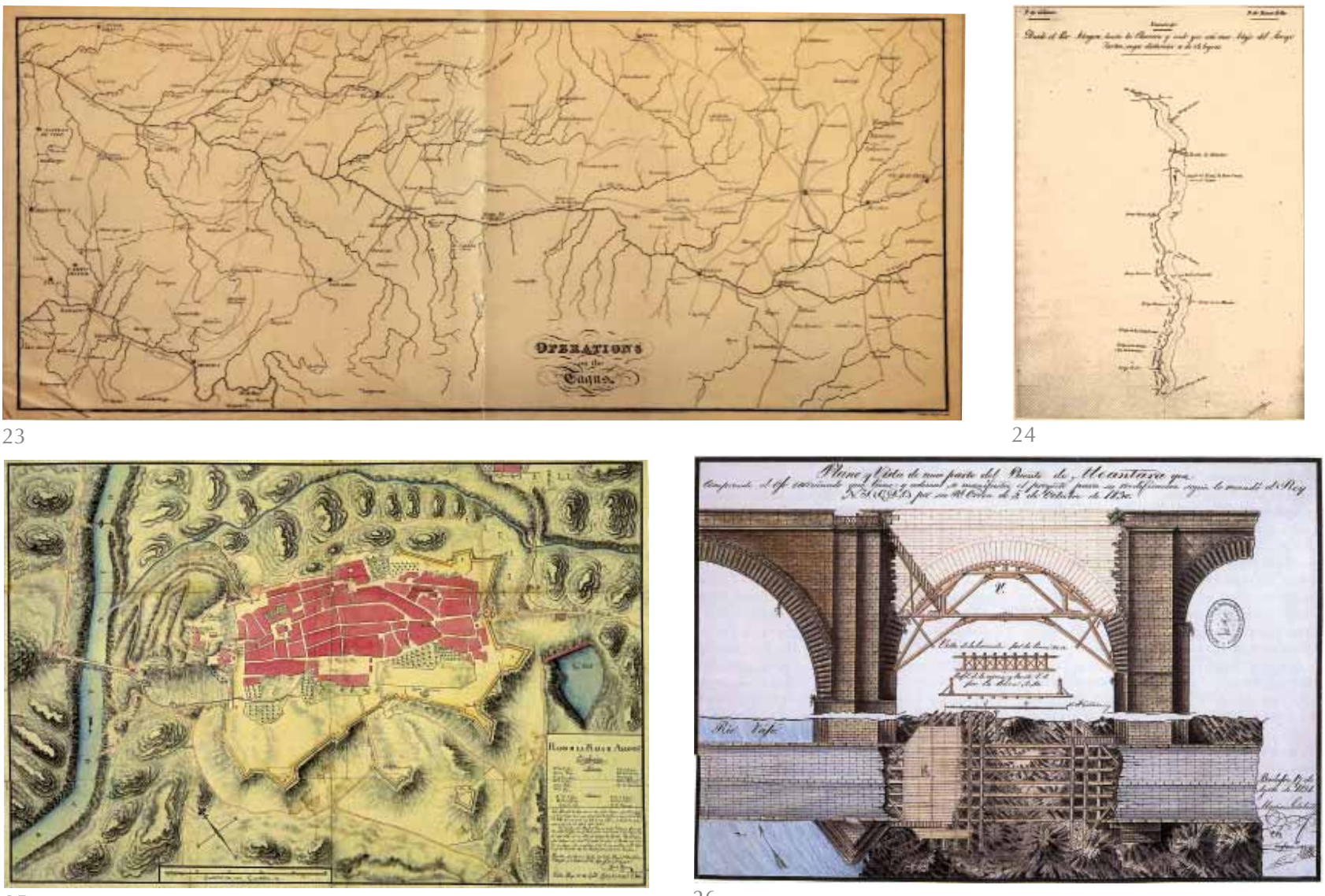

algunas de ellas que fueron copiadas numerosas veces y con fortuna variable. Estas vistas permitieron difundir el patrimonio cultural y turístico de los países en numerosas publicaciones y revistas periódicas con las facilidades que aportaba la técnica de la litografía, desempeñando una función similar a la que posteriormente realizaría la fotografía. Además, proporcionaban una idea suficientemente aproximada del entorno de los monumentos e incluso de las costumbres de los habitantes, resultando en muchos casos, como el de Gustave Doré, bastante realistas o incluso caricaturizantes.

El mejor ejemplo de estas series lo constituyen las imágenes incluidas por Alexandre Laborde en su obra Voyage pittoresque et literaire de I'Espagne (1805-1816), en la que incluyó varias vistas del puente y un detaIlado levantamiento (Figura 19), que fueron objeto de diferentes reinterpretaciones posteriores de calidad variable (Figuras 20 y 21), y que una vez generalizado el uso de la fotografía, fueron cediendo su lugar a ésta en las publicaciones ilustradas (Figura 22).

Durante el reinado de Carlos IV se adoptaron algunas decisiones que iban a afectar a la redacción de cartografía, como fueron la creación de la Inspección General de Caminos en 1799 y la segregación del ramo de las obras públicas en 1803, merced a la cual los técnicos de aquélla habrían de integrarse en el Cuerpo de Ingenieros de Caminos y Canales, para cuya formación Agustín de Betancourt fundaría en Madrid en 1802 la Escuela homónima, quedando desde entonces los ingenieros militares sin competencias en la obra pública.

La guerra de la Independencia supuso, por una parte, un paréntesis en la actividad académica, pero por otra desencadenó una renovada necesidad de documentación cartográfica cuya elaboración recayó esencialmente en los ingenieros militares. La creación en 1810 del Cuerpo de Estado Mayor incluyó la del Depósito de la Guerra, cuyo cometido habría de ser "conservar la documentación histórica, geográfica y topográfica" que se iba realizando .

Muchos fueron los planos que se levantaron entonces sobre el curso del Tajo, los territorios y fortificaciones extremeños, entre los que podríamos citar los del capitán Antonio Taona Ugarte (1810), Fernando Gabriel [1810], los ingenieros del Estado Mayor del $5^{\circ}$ y $6^{\circ}$ Ejército [1811] [1813], Juan Cini [1811], José Martín Ortega (1811), el subteniente Mariano García (1812), Benito Méndez (1812), el teniente coronel José Aguado (1812) (1813), Blas Teruel (1813) e incluso de batallas como la de Albuhera en Badajoz (1811) dibujados por nuestro Ejército y por los franceses y los ingleses en torno a los años 1812 y 1813.
23. Manuel Fondos, Plano de la Plaza de Alcántara (1812), Madrid, CGE. Aún representa la topografía por curvas de conción, pero muestra con detalle el caserío y los baluartes, así como el puente y sus accesos.

24. Anónimo inglés, Operations on the Tagus (1825). Centro de Información Cartográfica y Territorial de Extremadura (Badajoz, España).

25. Francisco Javier Cabanes y Agustín Marco Artu, Planos que representan el conocimiento de las riberas del Tajo. Verificados en 1641,1755 y 1828. Con objeto de arreglar la navegación de este Rio. Año de 1829, Biblioteca Nacional de España (Madrid, España).

26. Mariano Salaberry, Plano y vista de una parte del Puente de Alcántara que comprende el ojo arruinado que tiene; y además se manifiesta el proyecto para su reedificación según lo mandó el Rey N.S. (Q.D.G.) por su RI. Orden de 5 de Octubre de 1830. Archivo General Militar de Madrid, Instituto de Historia y Cultura Militar (Madrid, España). 

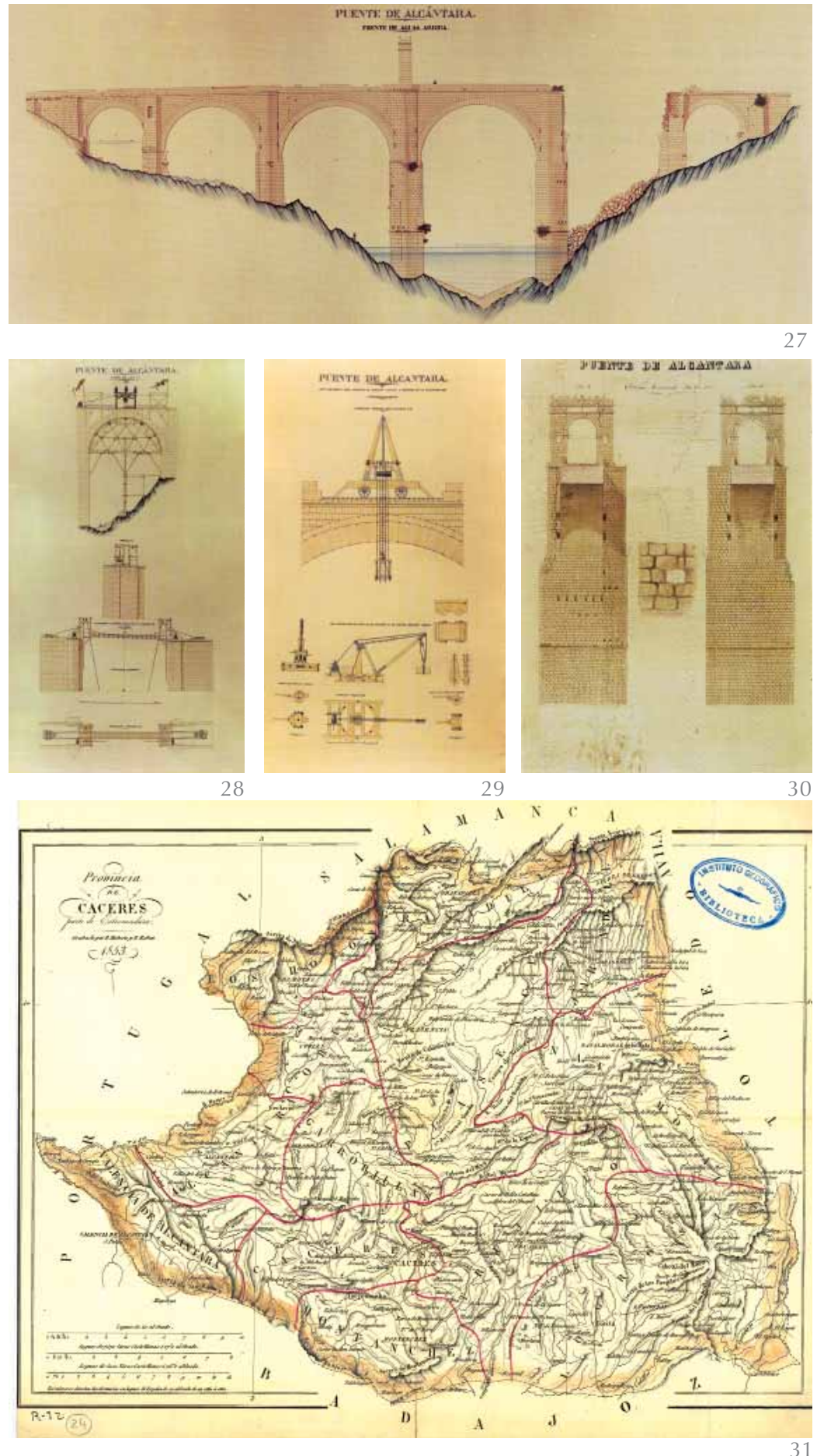

27. Alejandro Millán, Puente de Alcántara (1856). Archivo Iberdrola, (Inéditos). Levantamiento del alzado de aguas arriba antes de su reconstrucción.

28 y 29. Id. Cimbra y grúas diseñadas para llevar a cabo la construcción de la bóveda volada.

30. Id. Secciones transversales por la clave de la bóveda reconstruida, mostrando el despiece de la fábrica de sillería.

31. Ramon Alabern, Provincia de Cáceres (1853), Instituto Geográfico Nacional (Madrid, España).
La villa de Alcántara y su puente aparece representada desde entonces y a lo largo del siglo XIX en numerosas ocasiones como en los planos del capellán del Estado Mayor Manuel Fondos (1812) (Figura 23), que a veces incluían territorios más amplios (1812) [1813], los de Félix Coeli (1836), la Comandancia de Ingenieros (1851) o los realizados por el Ejército Francés hacia 1812.

A pesar de haber alcanzado la paz, sobre la zona se siguieron elaborando varias series Ejército Francés ca. 1820) y otros mapas militares como el de Tomás Benavides (1821) de itinerarios militares (Juan Donojaz 1817, o el de José Oñativia (1821), y se renovó el interés por reproducir las estrategias de algunos de los escenarios más significativos de la guerra como Arroyo Molinos (Fermín Arteta y Joseph Brito 1822, sobre otro de T. Cadell y W. Davies de 1813), el Tajo (1825) (Figura 24), o incluso toda la frontera portuguesa (1827).

Coincidiendo con el segundo cierre reaccionario de la Escuela de Ingenieros de Caminos entre 1823 y 1833 por el inefable rey Fernando VII (el primero había tenido lugar entre 1814 y 1820), el entonces Secretario de Estado Luis López Ballesteros para impulsar las obras públicas encargó a Agustín Larramendi la dirección facultativa de aquéllas, y éste consiguió reunir a algunos de sus miembros e incluso a algún emigrado (1:350).

Aprovechando esta coyuntura y como antes hemos citado, en 1828 el brigadier de infantería Francisco Javier Cabanes obtuvo licencia para hacer los estudios oportunos del cauce del Tajo para plantear una línea de vaporcitos de seis pies de calado entre Aranjuez y Lisboa. El proyecto, impreso con el título Memoria que tiene por objeto manifestar la posibilidad de hacer navegable el río Tajo desde Aranjuez hasta el Atlántico (Madrid, Imprenta de D. Miguel de Burgos, 1829), se acompañó de un volumen de Planos que representan el conocimiento de las riberas del Tajo. Verificados en 1641, 1755 y 1828 . Con objeto de arreglar la navegación de este Rio (Año de 1829. Imp. Lith. de Engelmann \& Cie. Litographe de la Chambre et du Cabinet du Roi. A Paris-Faubourg Montmartre $n^{\circ} 6$ ). Éste se imprimió en París probablemente para asegurar la calidad de los planos. En el trabajo colaboró activamente el arquitecto Agustín Marco Artu (21:151), y el plano correspondiente al tramo de Alcántara se recoge en las láminas nos 32 (pág. 42) y 40 (pág. 112), aunque aportan poco respecto al plano de Carduchi pero se extienden más hacia el este; incluyen parte del camino de sirga construido por Antonelli y representan el puente romano cortado en el estribo norte, como consecuencia de las voladuras de la guerra de la Independencia (Figura 25).

No se llevó a cabo tal proyecto, aunque no se desistió definitivamente y siguieron realizándose reconocimientos de los diferentes tramos del río por parte de la Jefatura de Obras Públicas (1858) para intentar reinstaurar la navegación.

\section{HACIA LA PRECISIÓN CARTOGRÁFICA}

Por entonces el puente de Alcántara había acusado los deterioros sufridos durante la 


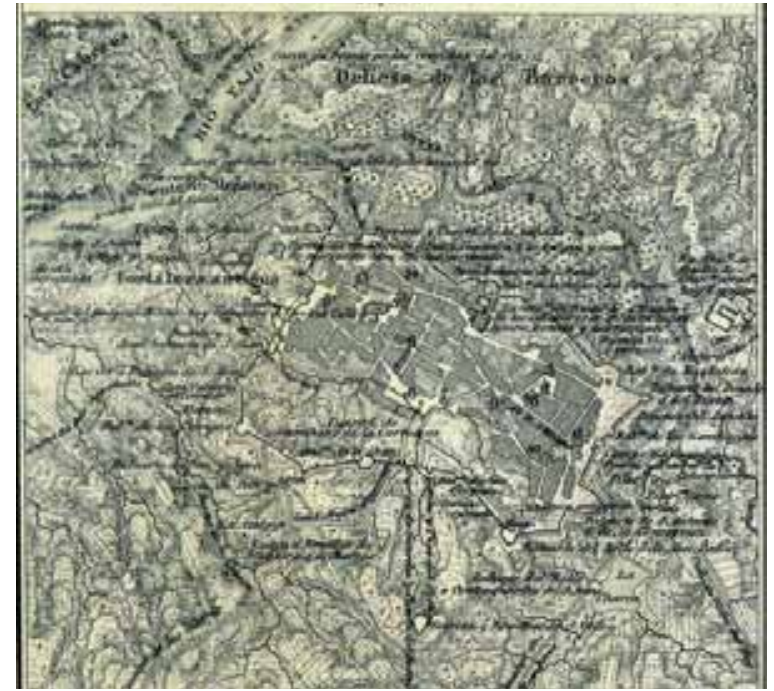

guerra y, por el peligro que entrañaban los pasos provisionales en madera o los alternativos por otros puntos del cauce, se hizo urgente plantear una solución a la destrucción completa de la segunda bóveda desde la margen septentrional que había causado una voladura de los franceses. Una de las propuestas se planteó en 1830, según proyecto de Mariano Salaberry (Figura 26), y consistía en reconstruir la bóveda con la misma fábrica utilizando una cimbra de madera. Puede apreciarse el cambio fundamental en el grafismo que plantea este proyecto respecto al anterior -en un siglode Geisto, en la línea de los dibujos que se proponían entonces en la École des Ponts et Chaussées, representando el puente en diédrico, delineado cuidadosamente en varias tintas y coloreado a mano con aguadas.

Las obras no se realizaron y la fábrica del puente llegó a mediados de siglo en el mismo estado de deterioro en que había quedado tras la guerra de la Independencia, de modo que en 1856 se volvió a plantear su reparación, encargándose esta vez del proyecto el ingeniero de caminos Alejandro Millán.

Millán realizó en primer lugar un cuidadoso levantamiento del estado del puente para definir sus patologías, que incluían no sólo la desaparición de la bóveda hasta sus arranques, sino también la invasión de especies vegetales. También hizo un proyecto detallado de la maquinaria y la cimbra necesarias para la construcción de la bóveda. El estado final también se detallaba en los planos de Millán, llegando a describir incluso el despiece de las fábricas. En general, puede observarse en estos documentos una mayor tendencia a la concreción a lo necesario a costa de evitar decoraciones y preciosismos gráficos innecesarios, como sucedía en los planos de Salaberry (Figura $27,28,29$ y 30). El proyecto se realizó y desde entonces no ha requerido más que pequeñas obras puntuales de consolidación, además de la gran operación de recalce de una de las pilas, cuyo precario estado quedó en evidencia con motivo del primer embalse tras la construcción de la presa.

La misma precisión que reflejan los planos de Salaberry y de Millán se refleja en la cartografía a pequeña escala de los mapas provinciales del geógrafo francés Auguste Henri Dufour (1837) y de Ramón Alabern (1853) (1865) (Figura 31); merece destacarse por su calidad la obra cartográfica de Francisco Coello, en gran parte ilustrando como un Atlas de España el Diccionario de Pascual Madoz (1840-70) (Figura 32), pero también como productor de mapas a escalas variadas sobre los territorios comprendidos entre el Tajo y el Guadiana [1859].

Esta última mitad del siglo se caracterizó por una gran producción cartográfica, mucha de ella procedente de organismos no militares, y la proliferación de cartografía temática y comercial, la mayoría realizada a pequeña escala.

Entre la producción temática merece destacarse la relacionada con Obras Públicas, como el trazado del ferrocarril de Ciudad Real a Badajoz (1860) o el de Talavera de la Reina a Cáceres por el ingeniero Mariano Cervigón (1861); el de los caminos de Extremadura de José de Castro (1862); el provincial de obras públicas (1865-70) y los realizados por José Méndez con igual tema (1900). No menos interesantes son los mapas geológicos de la zona, como los realizados por los ingenieros de minas Justo Egozcue y Lucas Mallada [1880].

Entre la cartografía comercial se pueden citar los mapas provinciales litografiados por B. Cuaranta y editados por Rubio, Grilo y Vitturi (1860) (1880), el de J. De la Puerta

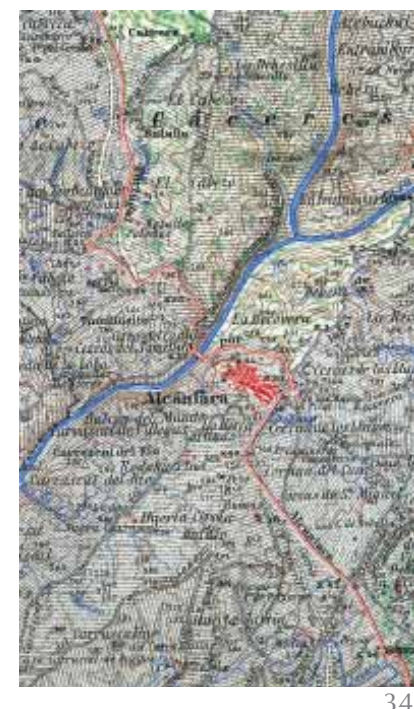

32. Francisco Coello, Alcántara. Plano incluido en el Diccionario. (1840-1870) de Pascual Madoz. Tuvo muchas dificultades para acceder a los levantamientos de Estado Mayor, por lo que recurrió al Dépôt de la Guerre en París para obtener información precisa de los levantamientos realizados por los franceses desde la Revolución.

33. Benito Chías y Carbó, Cáceres (1900). Pertenece a la serie de mapas provinciales que realizara, con fines didácticos, este in geniero militar (Col. particular).

34. Mapa Topográfico Nacional, Hoja 648 (ed. 1946). Detalle de la zona de Alcántara antes de la construcción de la presa. La representación del relieve por el método de las curvas de nivel, ideado por el Cruquius y sistematizado por Marcellin Du Carla (1780), tardó en ser aplicado a la topografía terrestre por la dificultad que entrañaba obtener suficientes puntos acotados. Obsérvese el trazado de la caminería antigua, de las cañadas, cordeles y veredas, así como la abundante toponimia. 
Vizcaíno (1860), los de Emilio Valverde recogidos en su Atlas Geográfico Descriptivo de la Península Ibérica (1880), los de $\mathrm{M}$. Pompido (1900) o los del ingeniero militar Benito Chías y Carbó, recogidos en el Atlas geográfico Ilamado España Regional acompañando a textos de Ceferino Rocafort y Casimiro Dalmau (1900) (Figura 33).

Entre los ejemplos de cartografía militar de este fin de siglo se pueden citar, además de los numerosos planos de las diferentes fortificaciones, los de reconocimiento de territorios como el del Tajo realizado por la Comandancia de Operaciones (1866), los de la comandancia de Cáceres realizado por los Carabineros [1875], los mapas itinerarios levantados por el Cuerpo de Estado Mayor (1882) (1887), los que recreaban escenarios de batallas (1876) y las estrategias utilizadas, como los del general Arteche [1885], o los realizados por Francisco Tiralso y Moreno de la Geografía Militar de España (1900).

Finalmente habría que destacar la labor cartográfica desarrollada por el Instituto Geográfico y Estadístico en la producción de planimetrías (1897-1902) y en las hojas del Mapa Topográfico Nacional a escala 1:50.000, cuya información sobre el territorio en materia de toponimia, caminería antigua y travesías de ríos y pasos de montaña históricos es excepcional, especialmente en las ediciones antiguas (Figura 34).

\section{BIBLIOGRAFÍA}

(1) Alzola y Minondo, P. 1979. Historia de las Obras Públicas en España. Madrid, Colegio de Ingenieros de Caminos, Canales y Puertos.

(2) Andrews, J.H. 2005. "Meaning, knowledge and power in the philosophy of maps". En J.B. Harley, The new nature of maps. Essays in the history of cartography. Baltimore, Maryland, The Johns Hopkins University Press, 21-58.

(3) Bouza Álvarez, F. 1995. "Cultura de lo geográfico y uso de la geografía entre España y los Países bajos durante los siglos XVI y XVII", en De Mercator a Blaeu. España y la Edad de Oro de la cartografía en las diecisiete provincias de los Países Bajos. Madrid.

(4) Bragard, P. 1997. Dictionnaire biographique des ingenieurs militaires dans les Pays Bas espagnols (1504-1713). Tesis doctoral inédita, Universidad Louvain-la-Neuve.

(5) Cámara, A. (Coord.) 2005. Los Ingenieros Militares de la Monarquía Hispánica en los siglos XVII y XVIII. Madrid, Ministerio de Defensa,

(6) Campos, F.J. 2008. Las Relaciones Topográficas de Felipe II: Índices, Fuentes y Bibliografía. http:// rcumariacristina.com/.

(7) Campesino, A. 2006. Fortificaciones abaluartadas de Extremadura: planos inéditos de Moraleja, Zarça de Alcántara, Alcántara, Valencia de Alcántara y Alburquerque. http://www.dipbadajoz.es/ publicaciones/.

(8) Capel, H. et al. 1983. Los ingenieros militares en España. Siglo XVIII. Publicacions de la Universitat de Barcelona.

(9) Cassani, J. 1705. Escuela militar de fortificación ofensiva y defensiva. Arte de fuegos y de escuadronar. Madrid.

(10) Chías, P. y T. Abad. 2004. Los caminos y la construcción del territorio en Zamora. Catálogo de puentes. Zamora / Madrid: CSIC / CEHOPU.

(11) Chías, P. y T. Abad. 2007. "A GIS in Cultural Heritage based upon multiformat databases and hypermedial personalized queries". ISPRS Archives XXXVI-5: 222-226.

(12) Chías, P. y T. Abad. 2008. "Las vías de comunicación en la cartografía histórica de la cuenca del Duero: construcción del territorio y paisaje". Ingeniería Civil 149: 79-91.

(13) Chías, P. y T. Abad. 2008. "La construcción del territorio: caminos y puentes en Castilla y León." En Las Obras Públicas en Castilla y León. Ingeniería, territorio y patrimonio. CICCP, Junta de Castilla-León, Valladolid, pp. 299-414.

(14) Commission of the European Communities. 2005. 12010: Digital Libraries. Brusselas.

(15) Delano-Smith, C. 2007. "Signs on Printed Topographical maps, ca. 1470-ca. 1640", en D. Woodward (ed.), The History of Cartography. Vol. III: Cartography in the European Reanaissance, Part I, pp. 528-590. Chicago, The University of Chicago Press.

(16) Harley, J.B. 1968. "The evaluation of early maps: Towards a methodology". Imago Mundi 22: 68-70.

(17) Harley, J.B. and D. Woodward 1987. "Preface". En J.B. Harley y D. Woodward, The history of cartography: Cartography in prehistoric, ancient, and medieval Europe and the Mediterranean. Chicago, The University of Chicago Press, Vol. I, xv-xxi.

(18) Harvey, P.D.A. 1980. Topographical maps. Symbols, pictures and surveys. London:, Thames and Hudson.

(19) Hevilla, M.C. 2001. "Reconocimiento practicado en la frontera de Portugal por el ingeniero militar Antonio Gaver en 1750", Biblio 3W. Revista Bibliográfica de Geografía y Ciencias Sociales, vol. VI, num. 335

(20) Kagan, R.L. 1998. Imágenes urbanas del mundo hispánico, 1493-1780. Madrid, Eds. El Viso.

(21) López Gómez, A. 1998. La navegación por el Tajo. El reconocimiento de Carduchi en 1641 y otros proyectos. Madrid, Real Academia de la Historia.

(22) Lucuze, P. de, 1772. Principios de fortificación, que contienen las definiciones de los términos principales de las obras de Plaza, y de Campaña, con una idea de la conducta regularmente observada en el Ataque, y Defensa de las Fortalezas. Dispuestos para la instrucción de la juventud militar por... Mariscal de Campo de los Reales Exercitos, y Director de la Real Academia de Matemáticas establecida en Barcelona. Barcelona, Thomas Piferrer. 